\title{
On the use of a simple tuned mass damper model for reducing the excessive vibration of tsunami evacuation suspension footbridge
}

\author{
Febrin Anas Ismail $^{1, *}$, Jafril Tanjung ${ }^{1}$, and Syah Bintang Aruan ${ }^{1}$ \\ ${ }^{1}$ Civil Engineering Department, Andalas University, Limau Manis, Padang, 25163, INDONESIA
}

\begin{abstract}
The suspension footbridges are commonly constructed in the rural area. The constructions method is relatively simple compared to other types of bridges, thus as consequence, the construction cost also becomes relatively cheaper. Therefore, the community-based construction may be applied to construct its type of the suspension footbridges. Unfortunately, due to their long span, slender and moderate weight, the footbridge construction has excessive vibration caused by the induce moving load such as pedestrian and motorcycle movements. This condition, however, will seriously unsafe when the footbridges are used for tsunami evacuating to the safe zone, such as in Padang city area. In this study, a simple Tuned Mass Damper (TMD) is proposed to reduce such kind of excessive vibration of the suspension footbridge mentioned above. The TMD is composed of the mass concrete and used the motorcycle or light car spring. The dynamic analysis by using the computer code based on the finite element method has shown the promising results. The excessive vibration of the analytical model of the suspension footbridge is significantly reduced. Its reduction is shown by the reduction of the vertical deformation of the suspension footbridge up to more than $90 \%$ compared to suspension footbridge without TMD. The type of suspension footbridge which using the current proposed TMD is recommended to be used in the tsunami-prone area such as for Batang Arau in Padang city.
\end{abstract}

\section{Introduction}

The Padang city in West Sumatra, Indonesia, is predicted to experience major earthquakes and tsunamis in the near future. In Padang city, the evacuation roads often have to cross the river, while the number of the existing bridges are limited. For instance, a river located in southern of Padang city, namely Batang Arau, has only three bridges, two of them are the type of suspension footbridges, as shown in Figure 1. Its river draws the line between the populated area and the evacuation high land area in Gunung Padang. The cost for constructing such kind of the suspension footbridge is relatively cheaper compare other types of bridges. The construction method for the suspension footbridge is also more simple when it compares to other types of the bridges in general. Moreover, the suspension footbridges in the rural area have been commonly constructed without proper detail engineering design. Thus, this bridge may be categorized as non-engineering bridges. The construction of the suspension footbridges is often long, slender and the weight is moderate. Therefore, the suspension footbridges are prone to successive vibration induced by moving load such as the pedestrian and motorcycle movements. Thus, it may become the danger in such moving of the evacuees when evacuating to high land safe zone in the southern part of Padang city.

Constructing addition of the suspension footbridges on the Batang Arau are recommended to overcome the limitation of the number of the bridges crossing it river. Easy, fast and low cost constructing are the main features of this type of the suspension footbridge. Thus, the suspension footbridge may be conducted in community-based construction without difficulty. In order to reduce the successive vibration induced by the moving load, a simple

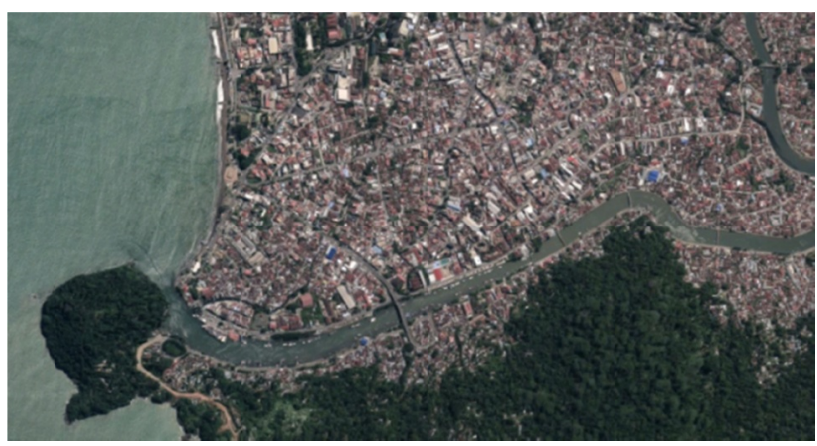

Fig. 1. Satellite image of Batang Arau (Source: Google Maps)

* Corresponding author: febrin@eng.unand.ac.id 


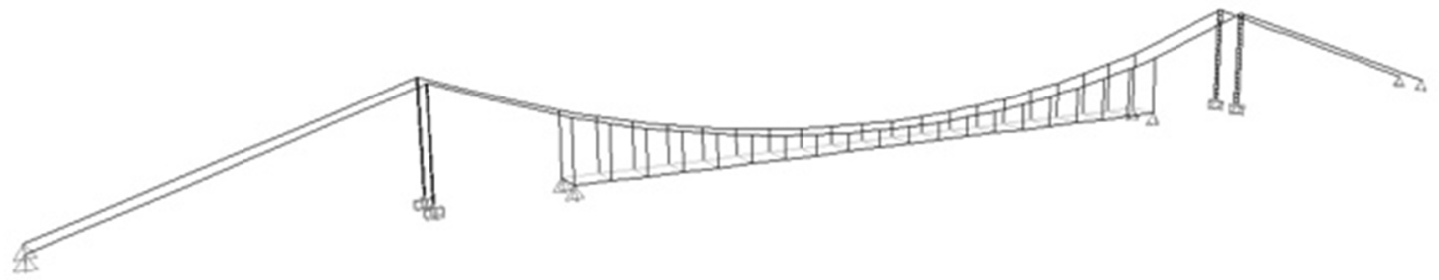

Fig. 2. Analytical model of suspension footbridge.

Tuned Mass Damper (TMD) has been proposed in this study. The TMD was assembled from mass concrete and used the motorcycle or light car springs. A series of analytical study has been addressed suitably in the design cycle as well as in the safety and comfort assessment of this suspension footbridge. For this purpose, the computer based on the dynamic finite element method, SAP2000, has been used.

Indeed, TMDs have been widely used for reduction of the vibration of the civil structures and mostly used for heavy load and hi-vibrate bridge structures such as railway bridges. The comprehensive discussed it topic has been well-documented by Latifi and Razani [1], Shetty et.al. [2] and Mehrabi et.al. [3]. Due to its advantages, easy to apply and simple construction, the TMDs, recently, often used to reduce the successive vibration of the existing footbridge as well as the pedestrian bridge structures [4] - [6]. By analytical study, Chen and Kareem [7] and Kala et.at. [8], as well as Carpineto et.al. [9], have also succeeded when evaluating the effects of the TMD to the dynamic responses of the pedestrian bridge structures.

\section{Analytical model}

Table 1. Material properties.

\begin{tabular}{|c|c|c|c|}
\hline Member & Type & $\begin{array}{c}\text { Elastic } \\
\text { Modulus } \\
\left.\mathbf{( k g f} / \mathbf{m}^{2}\right)\end{array}$ & $\begin{array}{c}\text { Density } \\
\mathbf{~ k g f / \mathbf { m } ^ { 3 }}\end{array}$ \\
\hline Pylon & $\begin{array}{c}\text { Steel } \\
\text { IWF } \\
\text { Steel } \\
\text { L 100.100.6 }\end{array}$ & $2,0 \times 10^{11}$ & 7850 \\
\hline Main Girder & $\begin{array}{c}\text { Timber } \\
\square 60.100\end{array}$ & $1,5 \times 10^{10}$ & 640 \\
\hline Cross & $\begin{array}{c}\text { Steel } \\
\text { G 65.42.5,5.8 }\end{array}$ & $2,0 \times 10^{11}$ & 7850 \\
\hline Cable & $\begin{array}{c}\text { Steel } \\
\text { Tendon dia. } 30\end{array}$ & $2,0 \times 10^{11}$ & 7850 \\
\hline Hanger & $\begin{array}{c}\text { Steel } \\
\text { Pipe } 13,8.2,3\end{array}$ & $2,0 \times 10^{11}$ & 7850 \\
\hline Plate & $\begin{array}{c}\text { Timber } \\
\square 30.120\end{array}$ & $1,5 \times 10^{10}$ & 640 \\
\hline
\end{tabular}

Figure 1. shows an analytical model of currently considered suspension footbridge structure. The model was analysed by using commercial computer software based on the finite element method, i.e. SAP2000. In the analysis, all the materials used in the suspension footbridge model were assumed to be homogeneous elastic linear materials as are tabulated in Table 1.

The linear elastic modal and time history analyses were performed to evaluate the performance of the TMDs in the suspension footbridge. The time history analysis was conducted due to applied moving loads. Three types of the moving loads, as it is shown in Fig. 2, have been defined for this purpose. The first type of moving load was applied when the load entering and leaving the footbridge, while the second and third types move along the span of the footbridge. The dynamic responses of the analytical model were obtained by integrating the equation of motion in the time domain by using the available Hilber-Hughes-Taylor method. The integration parameters were taken as follow, $\alpha=0$, $\beta=0,25$ and $\gamma=0,5[10]$.

In order to evaluate the performance of the current simple proposed TMD, four analytical models have been prepared. One model without TMD (WO) and others three models were used TMD, i.e. was attached at the bottom of the center span of the footbridge (WC), at bottom of the quarter span of the footbridge (WQ) and at bottom of the center and quarter span of the footbridge (WCQ). The matrix of this analytical works is tabulated in Table 2.

Table 2. The matrix of the analytical study.

\begin{tabular}{|c|c|}
\hline Analytical Works & Code \\
\hline Bridge without TMD & WO \\
\hline $\begin{array}{c}\text { Bridge with TMD at Middle of } \\
\text { Bridge Span }\end{array}$ & WC \\
\hline $\begin{array}{c}\text { Bridge with TMD at Quarter of } \\
\text { Bridge Span }\end{array}$ & WQ \\
\hline $\begin{array}{c}\text { Bridge with TMD at Middle } \\
\text { and Quarter of Bridge Span }\end{array}$ & WCQ \\
\hline
\end{tabular}


The proposed TDM in this study was designed as follow. The mass of TDM was taken about $4 \%$ the total weight of the footbridge, exclude the pylon. The stiffness of the TDM was defined as the square of the frequency of a first mode shape of the analytical model, multiply by the mass of the footbridge. The resumed properties of the current proposed TDM is given in Table 3. In SAP2000 computer software, the TDM is modeled as a LINK with Damper Friction Spring [10].

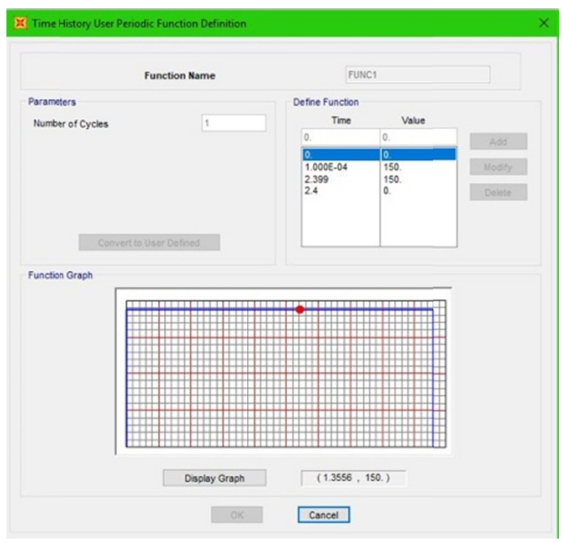

(a) Move load type 1

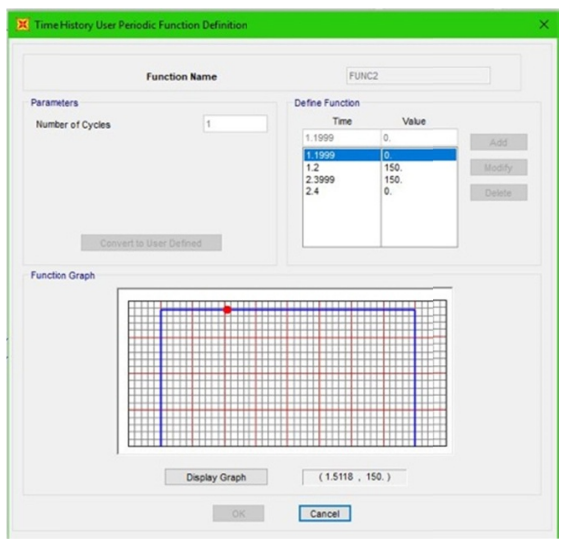

(b) Move load type 2

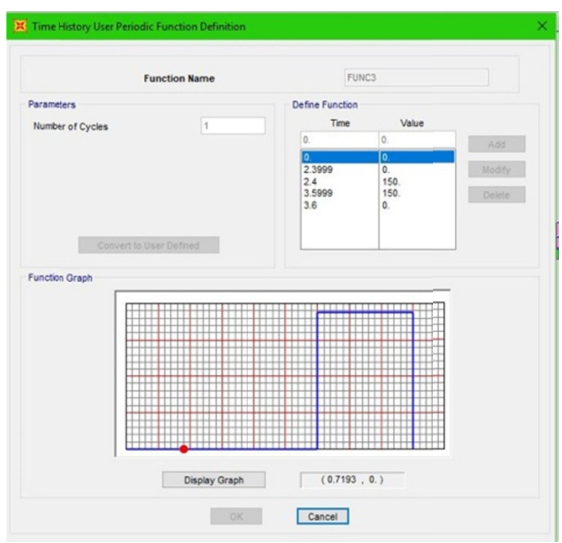

(c) Move load type 3
Table 3. Properties of TDM.

\begin{tabular}{|c|c|c|c|}
\hline Property & Symbol & Unit & Value \\
\hline Frequency & $\mathrm{f}$ & $\mathrm{Hz}$ & 1.06 \\
\hline Mass & $\mathrm{m}$ & $\mathrm{kg}$ & 71.21 \\
\hline Stiffness & $\mathrm{k}$ & $\mathrm{kg} / \mathrm{m}^{2}$ & 80.21 \\
\hline
\end{tabular}

\section{Analysis results and discussion}

Modal analysis was conducted based on linear eigenvalue analysis, which was used to find the natural frequency of structure and corresponding mode shapes. From the modal analysis in this study, twelve modes of vibration of the suspension footbridge structure were obtained. As it was mentioned above that the frequency of the first mode was used in calculating the mass and the stiffness of the TMD. The schematic image of the proposed TMD is shown in Fig. 3. Length of the spring used for TMD, i.e. $25 \mathrm{~cm}$, was defined based on the accumulation of the maximum amplitude of the TMD and the free space on the TMD.
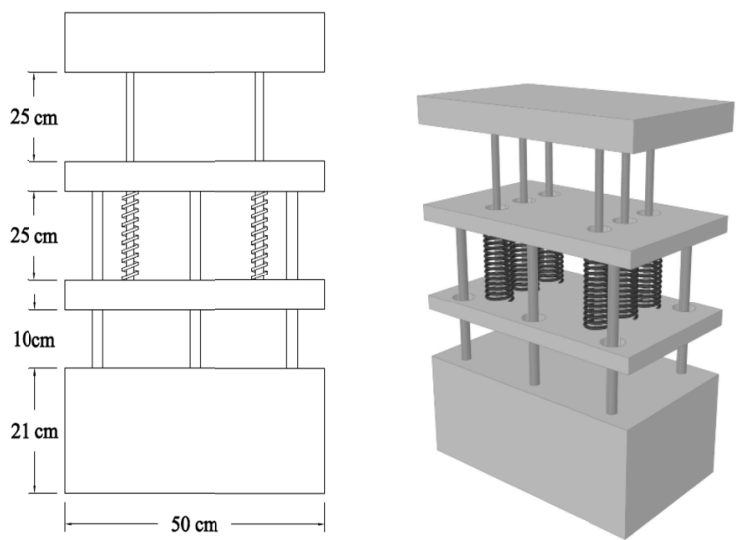

Fig. 4. Images of proposed TMD.

The excellent performance of the proposed TMD is also exposed by the comparison of the images first mode shape of vibration of all analytical models as it is shown in Fig. 4. The footbridge without TMD vibrate was swing more excessive compared to others footbridges attached the proposed TMDs. The linear elastic time history analysis was carried out due to applied moving load along the span of the footbridge. Comparison of dynamic responses in the term of vertical deformation along the span of the analytical model of each footbridge is shown in Fig. 5. A minus sign in the curve indicates the vertical deformation downward direction.

Fig. 3. Types of applied moving load. 


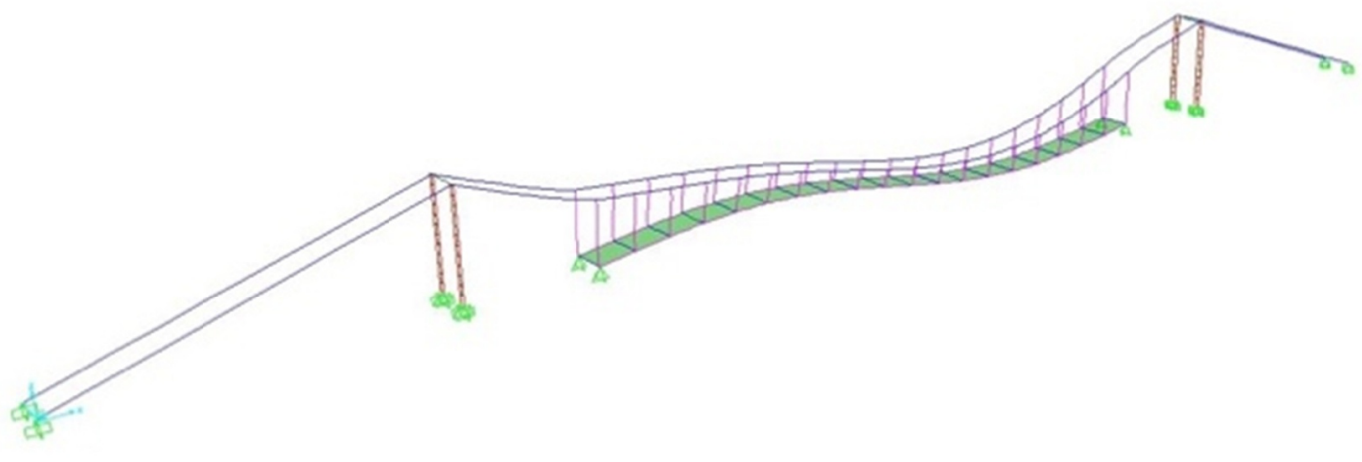

(a) Vibration model of WO model.

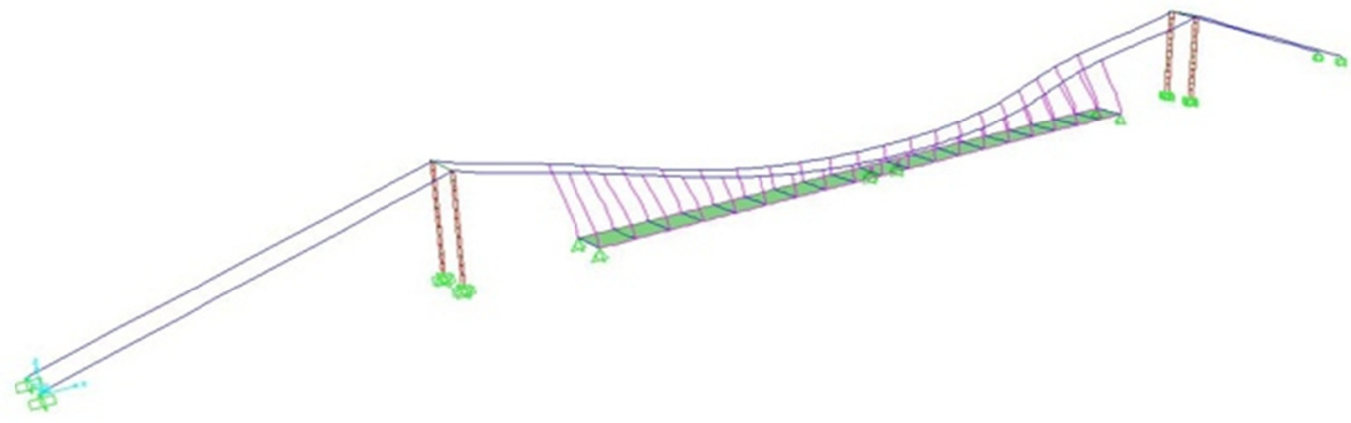

(b) Vibration mode of WC model.

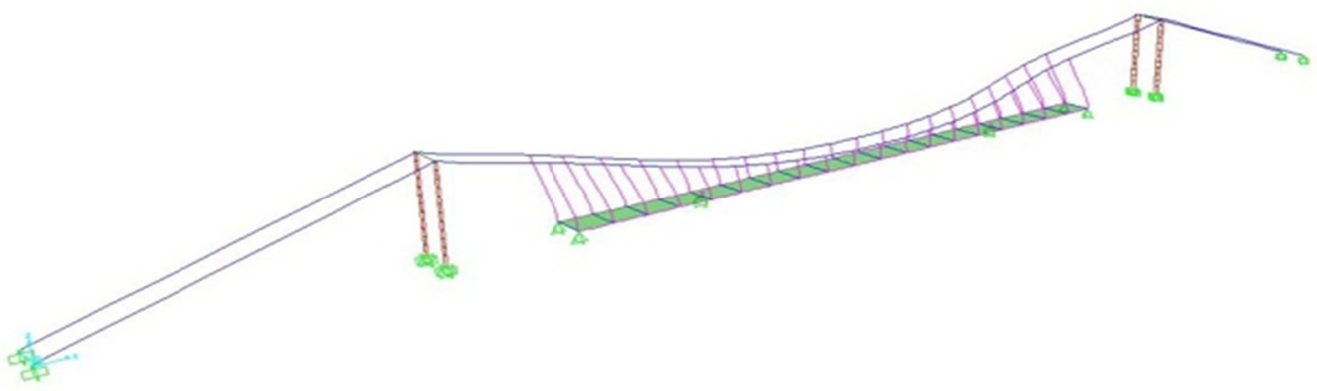

(c) Vibration mode of WQ model.

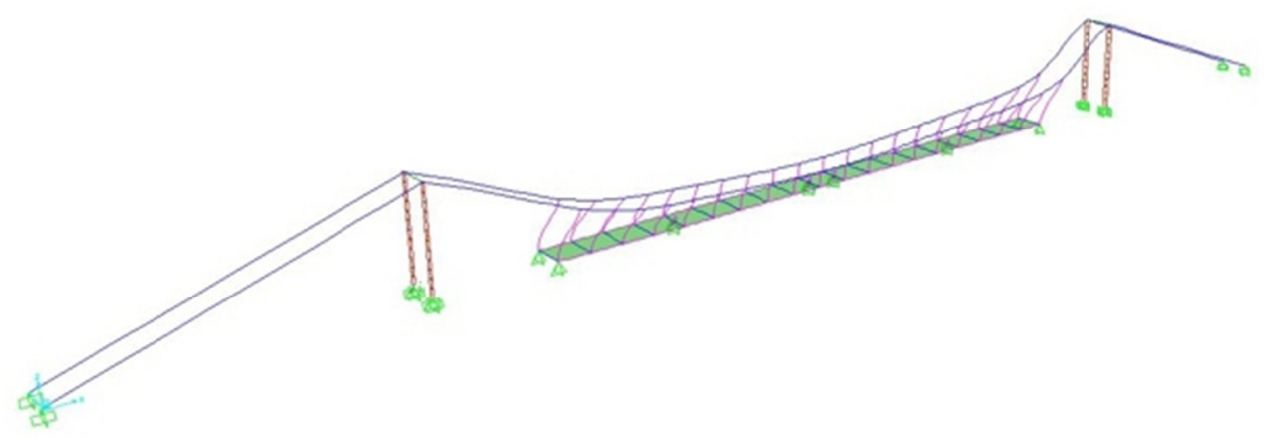

(d) Vibration mode of WCQ model

Fig. 5. Comparison of vibration mode of the analytical models. 


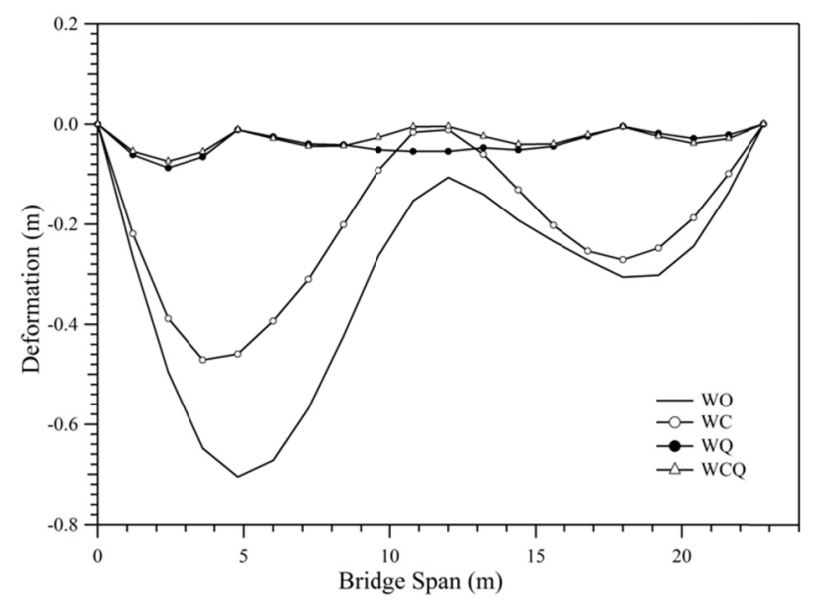

Fig. 6. Vertical deformation of the analytical models.

The comparison of analytical results has shown the superiority of the proposed TMD for reducing the vertical deformation along the span of the footbridge. An optimum position of TMD was obtained at the quarter span of the footbridge, i.e. the WQ model.

\section{Conclusion}

The analytical study for evaluating the proposed simple TMD has been conducted and discussed in this paper. The proposed simple TMD is composed of the mass concrete and used the motorcycle or light car springs. The analytical results by using computer code based on the finite element method, SAP2000, show that the proposed simple TMD succeeds to reduce the excessive vibration induced by the moving load. The use of simple TMD has significantly reduced the natural frequency and vertical deformation of the analytical model of the suspension footbridge. The analytical study also shows that the attached the TDM on the quarter span of the suspension footbridge has been given the optimum result to reduce it excessive vibration. Finally, the current proposed TMD is recommended to be used for the type of suspension footbridge construction in the tsunamiprone area such as for Batang Arau in Padang city.

\section{References}

1. R. Latifi and R. Razani, Periodica Polytechnic Mechanical Engineering 59(4), pp. 189-198, 2015 DOI: 10.3311/PPme.8327 (2015).

2. R. S. Shetty, M.H. Prashanth, T.M. Channappa, C.C. Ravikumar, International Journal of Civil and Structural Engineering, Vol 4, No 1 (2013).

3. A.B. Mehrabi, N.M. Telang and H. Tabatabai, Final Report for Highway-IDEA Project 7, Transportation Research Board, The National Academies (2003).

4. J. Maca, IOP Conf. Series: Materials Science and Engineering 236 (2017) 012060 doi:10.1088/1757899X/236/1/012060 (2017).

5. J. Habenberger, M. Kuhn, H. Tschamper and M. Fontana, First Middle East Conference on Smart
Monitoring, Assessment and Rehabilitation of Civil Structures, Dubai, UAE (2011).

6. W. Fiebig, Arch. Acoust., 35, 2, 165-174 (2010), DOI: 10.2478/v10168-010-0015-3 (2010).

7. X. Chen and A. Kareem, Journal of Structural Engineering (C) ASCE, DOI: 10.1061/ ASCE 073394452003 129:10 1291 (2003).

8. J. Kala, P. Hradil, V.Salajka and V. Juttner, The 10th International Conf. Modern Building Materials, Struct. and Techniques, Vilnius, Lithuania (2010).

9. N. Carpineto, W. Lacarbonara, and F. Vestroni, J. of Vibration and Control, 16(5): 749-776, 2010 DOI: 10.1177/1077546309350188 (2010).

10. CSI Analysis Reference Manual, 2016. 